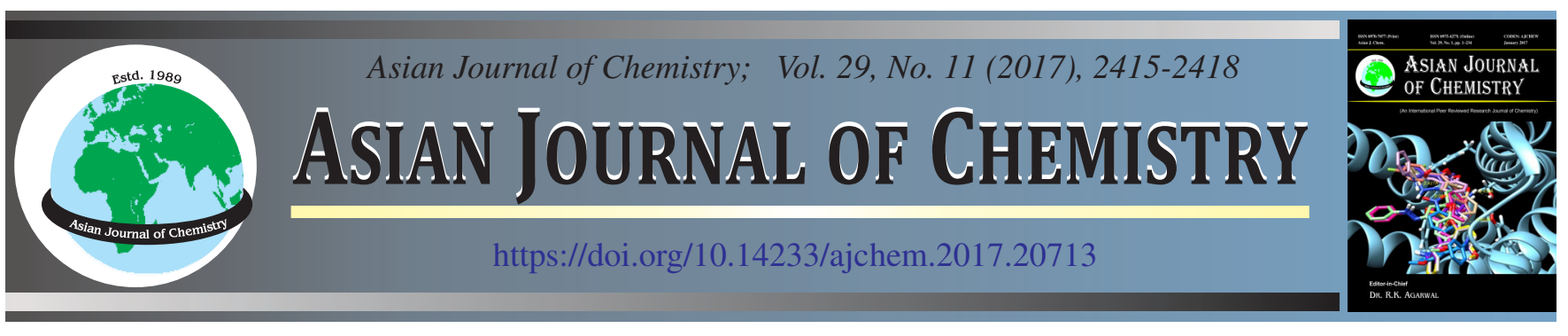

\title{
Green Synthesis, Characterization and Antimicrobial Activity of Silver Nanoparticles Using Leaf Extracts of Carissa carandas
}

\author{
Prabhakara Rao Dasari* and Prashant Anthony
}

Department of Chemistry, Sam Higginbottom University of Agriculture, Technology \& Sciences, Allahabad-211 007, India

*Corresponding author: E-mail: prabhakararao1986@gmail.com

In the present study, silver nanoparticles were synthesized from aqueous silver nitrate solution using leaf extracts of Carissa carandas and screening the activity of the synthesized nanoparticles against different microorganisms. Leaf extract was added to aqueous silver nitrate solution. After few hours colour of the solution changed from yellowish to brown. The confirmation of the nanoparticles was done by UVvisible spectroscopy; SEM and TEM analysis were done to further investigate the shape and size of the nanoparticles. TEM images reveal that the average size of the nanoparticles was $28 \mathrm{~nm}$. EDAX was used for the identification of multi-elements. The Carissa carandas plant leaf extracts are capable of producing silver nanoparticles extracellularly. The silver nanoparticles were quite stable in solution. The synthesized nanoparticles were screened for antimicrobial activity on five different microorganisms by agar well diffusion method. The nanoparticles have exhibited good antimicrobial activity against the five bacterial stains which were tested viz. Klebsiella pneumoniae, Bacillus cereus, Escherichia coli, Pseudomonas aeruginosa and Staphylococcus aureus. Out of these, synthesized silver nanoparticles have shown the best inhibition efficiency against Klebsiella pneumoniae.

Keywords: Carissa carandas, Silver nanoparticles, Green synthesis, Antimicrobial activity.

ᄂ $-\ldots \ldots-\ldots-\ldots-\ldots-\ldots-\ldots-\ldots-\ldots-\ldots-\ldots-\ldots$

\section{INTRODUCTION}

In recent years, the use of silver nanoparticles have rapidly increased due to their properties viz. optical, chemical, electric, photochemical, catalytic, magnetic and antibacterial [1]. Nanoparticles contain worthy properties to counter microorganisms. The most distinct and important properties of nanoparticles exhibit large surface area [2]. Recently, researchers have extensively worked on the silver, zinc oxide, copper oxide and gold nanoparticles and their applications in diagnostic, in optics and as catalysts. These nanoparticles are also playing an important role in medicinal and pharmaceutical fields $[3,4]$. The silver nanoparticles have attracted attention because of their advantages not only in the medicinal field but others fields like drug delivery, food technology, agriculture, textile industry, water treatment as well [5]. Now-a-days metal nanoparticles are preferably synthesized by chemical reduction methods but in previous years microwave and electrochemical techniques are used [6,7]. For synthesis of nanoparticles many methods were used such as chemical, physical and biological synthesis. In comparison to chemical methods which may induce, toxicity methods utilizing biological molecules extract from plants establish their superiority over chemical methods [8]. The biosynthesis of nanoparticles was very effective compared to other methods, and eco-friendly, suitable for large scales synthesis and this method is free from the requirement of high pressure, energy, toxic chemicals and temperature [9]. The application of silver nanoparticles in topical ointment and creams for infection of burns and wounds is well documented $[10,11]$. In many studies, the silver nanoparticles were screened as anticancer agents and in many positive results have been obtained therefore the silver nanoparticles may be developed as potent anticancer medicine [12,13]. The biosynthesis of silver nanoparticles utilizing different plants and plant parts such as Artocarpus heterophyllus [14], Desmodium triflorum [15], Tribulus terrestris [16], Boerhaavia diffusa [17], Moringa oleifera [18], Eucalyptus chapmaniana [19] have been reported. In the present study, we have synthesized silver nanoparticles using the leaf extract of Carissa carandas and tested their antimicrobial properties on five different bacteria viz. Escherichia coli, Klebsiella pneumoniae, Bacillus cereus, Pseudomonas aeruginosa and Staphylococcus aureus.

\section{EXPERIMENTAL}

Carissa carandas leaves were collected from Department of Horticulture, SHUATS campus, Allahabad, India. The Carissa carandas leaves were thoroughly washed and dried. All chemicals 
used were of all analytical grade. Silver nitrate purchased from (SD Fine Chemicals Limited, Mumbai, India) and deionized water was obtained from (LAB CHEM, Scientific agencies and general supplier, Allahabad, India. For antibacterial study Agar powder, peptone and beaf extract purchased from (HIMEDIA Laboratories Pvt. Ltd, Mumbai, India) and sodium chloride (Merck Limited, Mumbai, India).

Preparation of plant extract: The leaves of Carissa carandas were thoroughly washed with distilled water several times for removing the waste materials and then dried in shade at room temperature. The dried leaves were then powdered. To $3 \mathrm{~g}$ of powder leaves, $100 \mathrm{~mL}$ of deionized water was added and then heated for 5 to $10 \mathrm{~min}$ at $60{ }^{\circ} \mathrm{C}$. The aqueous extract was collected after filtration.

Synthesis of silver nanoparticles: Carissa carandas fresh leaves extract and silver nitrate $(1 \mathrm{mM})$ solution was mixed in the ratio of 1:10 with the help of rotary shaker for $30 \mathrm{~min}$. The solution was boiled over in water-bath at $60-80^{\circ} \mathrm{C}$ with constant stirring for $5 \mathrm{~min}$ and allowed to cool. Then the sample was kept into the incubator for $3 \mathrm{~h}$ in dark place, the colour changed from yellow to brown. It indicates synthesis of silver nanoparticles [20,21]. The solution after change of colour was used for further characterization of silver nanoparticles.

To check the bioreduction of silver ions to silver nanoparticles, the UV-visible spectroscopy (single beam) (Global instruments) was used. The absorbance was recorded for different wavelength range from $300-540 \mathrm{~nm}$. The deionized water used as a blank. For transmission electron microscopy (TEM, JEOL JEM-2100F operated at high voltage of $200.0 \mathrm{kV}$ ), Carissa carandas leaves extract silver nanoparticle suspension was dried on a carbon coated grid under IR lamp. For scanning electron microscopy-energy dispersive X-ray analysis (SEMEDAX, JSM-6510, JEOL/EO) analysis, the sample suspension was dried on stub under IR lamp. The gold-coated mixture was observed under the SEM at 5000x magnification range. The SEM was used for the microstructure, surface image or properties and size of the silver nanoparticles. Energy dispersive X-ray analysis was used for identifying the chemical composition of silver nanoparticles.

Antimicrobial activity: Freshly prepared agar media was used for the antibacterial activity. Nutrient agar media prepared with sodium chloride $5 \mathrm{~g}$, peptone $5 \mathrm{~g}$, beef extract $3 \mathrm{~g}$, agar $20 \mathrm{~g}$ and distilled water $1000 \mathrm{~mL}$. All these were mixed together and $\mathrm{pH} 7.4$ was adjusted using $\mathrm{HCl}$ and $\mathrm{NaOH}$ solutions. The antimicrobial activity of the synthesized silver nanoparticles was investigated by agar well diffusion method against five different bacterial strains viz., Escherichia coli, Klebsiella pneumoniae, Bacillus cereus, Pseudomonas aeruginosa and Staphylococcus aureus. These microorganisms were grown upon in nutrient agar broth media at $37^{\circ} \mathrm{C}$ for $24 \mathrm{~h}$. The plates were cleaned with distilled water and kept in the hot oven at $60^{\circ} \mathrm{C}$ in order to remove moisture content $[16,22]$. In the plates were poured with $10 \mathrm{~mL}$ of nutrient agar media. Four wells were arranged in each plate with the help of $6 \mathrm{~mm}$ borer; these wells were filled $75 \mu \mathrm{L}$ synthesized silver nanoparticles suspension. Finally, the plates were incubated at $37{ }^{\circ} \mathrm{C}$ for $24 \mathrm{~h}$ after which the inhibition was carefully observed for the inhibition zone, which appear as an area without the microbial growth. The diameters of the zones were measured with scale. All the analyses were done in triplicate and the mean diameters of inhibition with the standard deviation have been reported for each organism.

\section{RESULTS AND DISCUSSION}

UV-visible: The Carissa carandas leaves extract mixed with $(1 \mathrm{mM}) \mathrm{AgNO}_{3}$ solution, changed from yellow to brown colour in $20 \mathrm{~min}$ but dark brown colour appeared after $2 \mathrm{~h}$. The colour changing process indicates the presence of silver nanoparticles. The suspension was monitored by recording the absorbance wavelength from $340 \mathrm{~nm}$ to $540 \mathrm{~nm}$. The observed absorbance peak at $420 \mathrm{~nm}$ (Fig. 1) is due to the surface plasmon resonance $[16,21]$ and the appearance of peak shows the reduction of $\mathrm{Ag}^{+}$to silver nanoparticles hence it can be concluded that Carissa carandas leaf extract behaves as a reducing agent. The UV-visible analysis also showed that these nanoparticles were found to be stable even after six months.

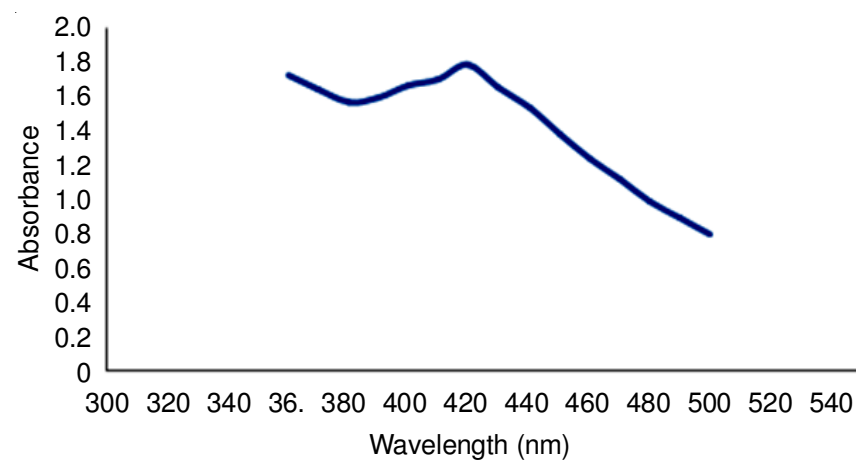

Fig. 1. UV-visible spectrum of silver nanoparticles of Carissa carandas leaves extract

TEM analysis of silver nanoparticles: The synthesized nanoparticles were uniform and circular in shape. TEM image of Carissa carandas silver nanoparticles (Fig. 2) showed the particles were well dispersed and diameter ranged from 20 to $38 \mathrm{~nm}$ and the minimum size of particle observed was $20 \mathrm{~nm}$ under at 100000× magnification ranges [22,23].

SEM analysis: Fig. 3(A) shows the SEM image of synthesized silver nanoparticles by Carissa carandas leaves extract. This image was captured at $5000 \times$ magnification scale and size of the nanoparticles observed was $40 \mathrm{~nm}$. In this micrograph, silver nanoparticles can be observed as clusters and microstructure because of aggregation of particles and evaporation of solvent during sample preparation, due to this some variations in the particle size. However, in these silver nanoparticles, different shapes were observed ranging from spherical, rod shape to irregular in shape [20,21].

EDX analysis of silver nanoparticles: The elemental composition of silver nanoparticles suspension was determined by SEM equipped with EDAX detector. In Fig. 3(B) the strong signal in silver region is observed and confirming the formation of silver nanoparticles. The metallic nanoparticle shows the typical optical absorption peak approximately at 1.8 to 2.983 $\mathrm{keV}$. The silver nanoparticles synthesized from leaves extract of Carissa carandas showed strong signal at $1.9 \mathrm{keV}$ due to the surface plasmon resonance. The other spectral signals observed 


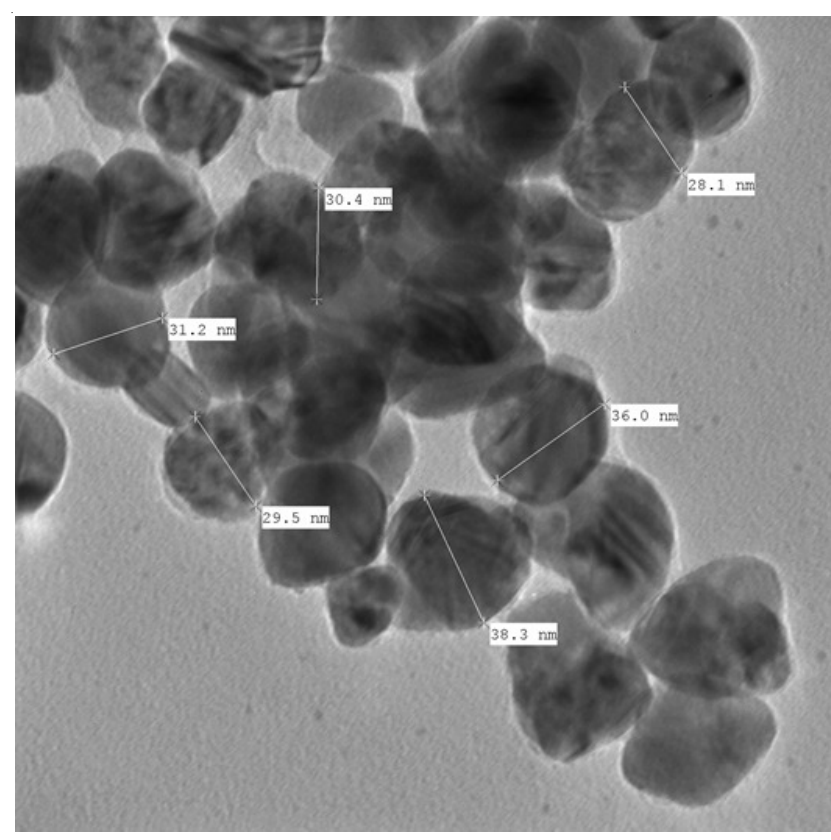

Fig. 2. TEM image of silver nanoparticles synthesized from Carissa carandas leaves extract
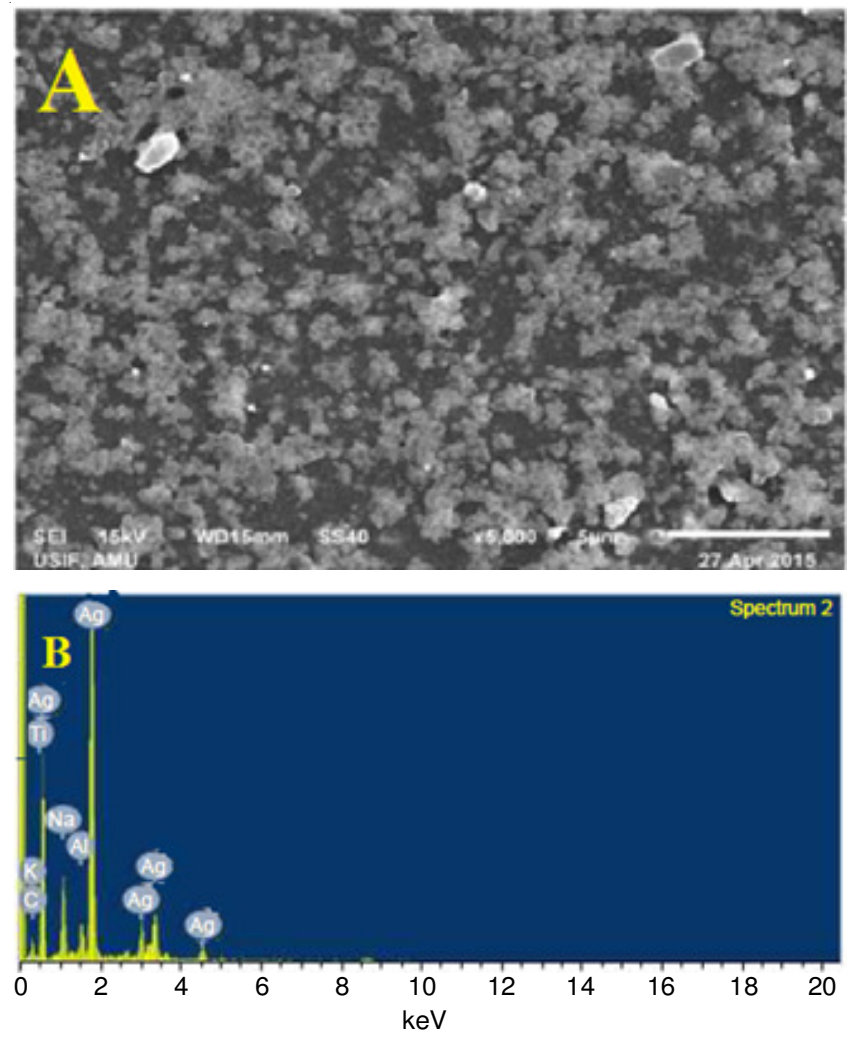

Fig. 3. (A) SEM image of the silver nanoparticles synthesized from Carissa carandas leaves extract, (B) EDX of silver nanoparticles synthesized by Carissa carandas leaves extract were of carbon, oxygen, potassium, aluminum, sodium and titanium, indicating extra cellular organic moieties from extract of plant leaves which were added during the sample preparation $[18,23]$.

Antimicrobial activity: The Carissa carandas leaves extract silver nanoparticles were tested for antibacterial activity on Gram positive bacteria such as Staphylococcus aureus, Bacillus cereus as well as Gram negative bacteria such as Escherichia coli, Pseudomonas aeruginosa and Klebsiella pneumoniae. The synthesized silver nanoparticles of Carissa carandas leaves extract, silver nitrate and ciprofloxacin drug was used as a standard antibiotic. The silver nanoparticles of Carissa carandas showed good activity on almost all the bacterial strains tested such as Klebsiella pneumoniae, Bacillus cereus and Escherichia coli $[23,24]$. The silver nanoparticles have shown even better inhibition zone in certain cases when compared with antibiotic ciprofloxacin (Table-1). These results of Carissa carandas silver nanoparticles were more effective at low concentration than ciprofloxacin. The synthesized silver nanoparticles have shown best activity on Klebsiella pneumoniae with a inhibition zone of $16.066 \pm 0.208 \mathrm{~mm}$. The better activity observed against gram negative bacterial may be due to the difference in the cell wall structure of the two bacterial strains.

\section{REFERENCES}

1. V.K. Sharma, R.A. Yngard and Y. Lin, Adv. Colloid Interface Sci., 145, 83 (2009); https://doi.org/10.1016/j.cis.2008.09.002.

2. S. Gurunathan, K. Kalishwaralal, R. Vaidyanathan, D. Venkataraman, S.R.K. Pandian, J. Muniyandi, N. Hariharan and S.H. Eom, Colloids Surf. B Biointerfaces, 74, 328 (2009); https://doi.org/10.1016/j.colsurfb.2009.07.048.

3. V. Parashar, R. Parashar, B. Sharma and A.C. Pandey, Dig. J. Nanomater. Biostruct., 4, 45 (2009).

4. M. Catauro, M.G. Raucci, F. De Gaetano and A. Marotta, J. Mater. Sci. Mater. Med., 15, 831 (2004); https://doi.org/10.1023/B:JMSM.0000032825.51052.00.

5. N.A. Begum, S. Mondal, S. Basu, R.A. Laskar and D. Mandal, Colloids Surf. B Biointerfaces, 71, 113 (2009);

https://doi.org/10.1016/j.colsurfb.2009.01.012.

6. M. Starowicz, B. Stypula and J. Banas, Electrochem. Commun., 8, 227 (2005); https://doi.org/10.1016/j.elecom.2005.11.018.

7. R.M. Tripathi, S. Antariksh, G. Nidhi, K. Hars and R.P. Singh, Dig. J. Nanomater. Biostruct., 5, 320 (2010).

8. S. Ahmed, M. Ahmad, B.L. Swami and S. Ikram, J. Adv. Res., 7, 17 (2016); https://doi.org/10.1016/j.jare.2015.02.007.

9. S. Kagithoju, V. Godishala and R.S. Nanna, Biotech, 5, 709 (2015); https://doi.org/10.1007/s13205-014-0272-3.

10. M. Lengke and G. Southam, Geochim. Cosmochim. Acta, 70, 3646 (2006); https://doi.org/10.1016/j.gca.2006.04.018.

11. C.J. Murphy, J. Mater. Chem., 18, 2173 (2008); https://doi.org/10.1039/B717456J.

\begin{tabular}{|c|c|c|c|c|}
\hline \multicolumn{5}{|c|}{$\begin{array}{l}\text { ANTIMICROBIAL ACTIVITY OF SILVER NANOPARTICLES FROM Carissa carandas EXTRACTS IN EACH } \\
\text { PETRI-DISH PLATE NANOPARTICLES (N), ANTIBIOTIC (A), SILVER NITRATE (N) AND EXTRACT (E) }\end{array}$} \\
\hline Name of the microorganisms & Nanoparticles (N) mm & Antibiotic (A) mm & Silver nitrate $(\mathrm{S}) \mathrm{mm}$ & Extract $(\mathrm{E}) \mathrm{mm}$ \\
\hline Klebsiella pneumoniae (-) & $16.066 \pm 0.208$ & 8 & 9 & 0 \\
\hline Bacillus cereus (+) & $15.833 \pm 0.152$ & 10 & $14.133 \pm 0.152$ & 0 \\
\hline Escherichia coli $(-)$ & $14.266 \pm 0.251$ & $10.133 \pm 0.152$ & $13.366 \pm 0.057$ & 0 \\
\hline Pseudomonas aeruginosa (-) & $14.233 \pm 0.152$ & 10 & 10 & 0 \\
\hline Staphylococcus aureus (+) & $14.166 \pm 0.152$ & 10 & 10 & 0 \\
\hline
\end{tabular}


12. R. Vaidyanathan, K. Kalishwaralal, S. Gopalram and S. Gurunathan, Biotechnol. Adv., 27, 924 (2009); https://doi.org/10.1016/j.biotechadv.2009.08.001.

13. K. Venugopal, H.A. Rather, K. Rajagopal, M.P. Shanthi, K. Sheriff, M Illiyas, E. Rather, S. Manikandan, M. Uvarajan, M. Bhaskar and M. Maaza, J. Photochem. Photobiol. B, 167, 282 (2017); https://doi.org/10.1016/j.jphotobiol.2016.12.013..

14. U.B. Jagtap and V.A. Bapat, Ind. Crops Prod., 46, 132 (2013); https://doi.org/10.1016/j.indcrop.2013.01.019.

15. N. Ahmad, S. Sharma, V.N. Singh, S.F. Shamsi, A. Fatma and B.R. Mehta, Biotechnol. Res. Int., 2011, 1 (2011); https://doi.org/10.4061/2011/454090.

16. V. Gopinath, D. MubarakAli, S. Priyadarshini, N.M. Priyadharsshini, N. Thajuddin and P. Velusamy, Colloids Surf. B Biointerfaces, 96, 69 (2012); https://doi.org/10.1016/j.colsurfb.2012.03.023

17. P.P.N. Vijay Kumar, S.V.N. Pammi, P. Kollu, K.V.V. Satyanarayana and U. Shameem, Ind. Crops Prod., 52, 562 (2014); https://doi.org/10.1016/j.indcrop.2013.10.050.

18. T.N.V.K.V. Prasad and E.K. Elumalai, Asian Pac. J. Trop. Biomed., 1, 439 (2011);

https://doi.org/10.1016/S2221-1691(11)60096-8.
19. G.M. Sulaiman, W.H. Mohammed, T.R. Marzoog, A.A.A. Al-Amiery, A.A.H. Kadhum and A.B. Mohamad, Asian Pac. J. Trop. Biomed., 3, 58 (2013); https://doi.org/10.1016/S2221-1691(13)60024-6.

20. C. Krishnaraj, E.G. Jagan, S. Rajasekar, P. Selvakumar, P.T. Kalaichelvan and N. Mohan, Colloids Surf. B Biointerfaces, 76, 50 (2010); https://doi.org/10.1016/j.colsurfb.2009.10.008.

21. N. Sahu, D. Soni, B. Chandrashekhar, B.K. Sarangi, D. Satpute and R.A. Pandey, Bioprocess Biosyst. Eng., 36, 999 (2013); https://doi.org/10.1007/s00449-012-0841-y.

22. P. Malairajan, G. Gopalakrishnan, S. Narasimhan and K.J.K. Veni, Int. J. Drug Dev. Res., 4, 133 (2012).

23. S. Kaviya, J. Santhanalakshmi, B. Viswanathan, J. Muthumary and K. Srinivasan, Spectrochim. Acta A Mol. Biomol. Spectrosc., 79, 594 (2011); https://doi.org/10.1016/i.saa.2011.03.040.

24. P. Dibrov, J. Dzioba, K.K. Gosink and C.C. Hase, Antimicrob. Agents Chemother, 46, 2668 (2002); https://doi.org/10.1128/AAC.46.8.2668-2670.2002. 